\title{
Un caso de fisura labiopalatina o "boca-de-lobo" en Makatampu, valle del Rímac, Perú, siglos XV-XVI
}

\author{
Alfredo J. Altamirano Enciso* \\ Marco Tulio A. García-Zapata**
}

\begin{abstract}
ALTAMIRANO ENCISO, A.J.; GARCÍA-ZAPATA, M.T.A. Un caso de fisura labiopalatina o "boca-de-lobo" en Makatampu, valle del Rimac, Perú, siglos XVXVI. Revista do Museu de Arqueologia e Etnologia, São Paulo, 20:361-380, 2010.
\end{abstract}

Resumo: É analisado um caso humano procedente do sítio arqueológico de Makatampu, vale do Rímac, costa central do Peru, com uma severa fenda palato-alveolar, gênero feminino, idade 30-35 anos, camponesa serrana que viveu durante o periodo Ichimay Tardio e instalação do império Inca, séculos XV-XVI d.C. A percentagem 0,41\% (um caso) de uma amostra de 241 individuos permitiu comparar duas hipóteses, uma de tipo biomédica que propõe que o lábio leporino tem como causa principal o uso exagerado de bebidas alcoólicas e/ou drogas praticadas intensivamente durante as festas oficiais andinas; a segunda hipótese é de cunho etnohistórico e antropológico que aponta que as sociedades da costa central praticavam casamentos endogâmicos no interior do ayllu. Esta evidência paleopatológica se reforça pelo registro pictórico dos huacos antropomórficos Mochica e da filologia indigena que a conheciam como qqoqya (quéchua) e santi (aimará).

Palavras-chave: Paleopatologia congênita - Fissura lábiopalatal - Incas Endogamia - Índios do Peru.

\section{Introducción}

- ntre enero y marzo de 1999, durante

C la ejecución del Proyecto Paleopatológico

Estudio de la Leishmaniasis de Forma Mucosa en Poblaciones Andinas realizada en el Museo

${ }^{*}$ ) Centro Brasileiro de Arqueologia, Rio de Janeiro. Universidad Nacional Mayor de San Marcos, Lima. <alfredo-altamirano@hotmail.com>

$\left.{ }^{(* *}\right)$ Instituto de Patologia Tropical e Saúde Publica da Universidade Federal de Goiás. <mctulianglobal@gmail.com>, <mctulianpg@gmail.com.>
Nacional de Arqueología, Antropologia e Historia del Perú (MNAAH), en Lima, fue descubierto un cráneo humano con clara evidencia de fisura labiopalatina (en adelante FLP). Por ser un material óseo inédito en la arqueologia andina y americana buscamos información sobre su contexto biocultural para enfocarlo dentro de dos hipótesis, una etnohistórica o tradicional y otra biomédica o reciente. La importancia de este descubrimiento rebasa los limites de la investigación paleopatológica y enriquece a la historia de la medicina y a las ciencias sociales y biomédicas.

Las malformaciones congénitas, embriopatias o teratológicas de los pueblos de los Andes 
Centrales como las alteraciones dentomaxilares, acrocráneo, albinismo, agenesia del conducto auditivo, atrofia de la columna, de los pies y brazos, espina bifida, gemelos, labio leporino, úvula bifida, mancha mongólica, rugosidad craneana o "chaqra uma", polidactilismo, meningocele, siamés, síndrome de Dawn, teratomas y osteomas, entre otras, ya habian sido registradas tanto en la literatura etnohistórica como en la cerámica mochica (Carod-Artal et al. 2006; Lastres 1943, 1951; Lastres y Cabieses 1959; Weiss 1984, Espinoza 1990).

FLP, "boca-de-lobo" o "fenda-de-lobo" es una malformación congénita del grupo del labio leporino caracterizado por la bipartición total o parcial de la región máxilofacial, produciendo una abertura o pasaje estrecha de la arcada dentaria superior. Los individuos nacidos con esta patología sufren durante la lactancia, la deglución, la fonación y, sobretodo, la estética (Gorlin et al. 1990; Winter 1997; Zimmerman et al. 1982). En el orbe a cada 11 minutos nace un bebé con esta embriopatia, atingiendo principalmente a los asiáticos mongólicos y amerindios. Entre ellos, de cada 700 recién nacidos uno presenta la afección, empero entre los blancos y negros, cae para uno en cada 1400 recién nacidos. Provoca el sindrome de Van der Woude que representa cerca del $2 \%$ de los casos de malformaciones labiopalatinas. Según la gravedad de la lesión el tratamiento más frecuente de corrección es la cirugia máxilofacial y la terapia de fonoaudiologia, y en diversos países de Sudamérica como Bolivia, Chile y Perú constituye un serio problema de salud pública (Menegotto y Salzano 1991; Minsal 2005; Murray 2002).

En la cerámica Mochica, especificamente en los huacos retratos de las fases II, III y IV, la representación del labio leporino es frecuente, indicando su presencia entre los valles de Lambayeque y Huarmey durante los siglos I-VII después de Cristo (Lastres 1943, 1951; Lastres y Cabieses 1959; Weiss 1984). Su representación iconográfica fue debatida entre los historiadores de la medicina desde inicios del siglo XX hasta los años 60 sin metodología rigurosa debido al fuerte dominio de la antropologia cultural estadounidense. Sin embargo, en la literatura paleopatológica andina no se había descrito ningún caso precolombino con contexto arqueológico para discutir las causas de su aparición en la antigüedad lo que nos permitió reevaluar el problema del labio leporino en los Andes Centrales (Allison 1974, 1993; Altamirano 1994; Cockburn 1988; Dalton et al. 1976; Lombardi 1994; Verano 1992; Verano y Lombardi 1999; Mendonça de Souza et alii 2008, 1994).

\section{El sitio}

Makatampu, Makat-Tampu o Maca-Tambo (MT) fue uno de los más extensos sitios arqueológicos del valle bajo del Rímac, lamentablemente destruido por el fenómeno de la expansión urbana y centralista de Lima en las décadas de 1940 y 1950. Sin embargo, gracias a las excavaciones de salvamento efectuadas en 1944 y a las fotos aéreas de ese mismo año, podemos percibir la magnitud de este complejo arqueológico en el valle (Narvaes 2002; Ravines 1985). ${ }^{1}$

El sitio se localizaba en la margen izquierda de este valle, distrito y provincia de Lima, a 84 $\mathrm{m}$ sobre el nivel del mar y a $5 \mathrm{Km}$ del océano Pacifico, entre Lima y el Callao en terrenos de la antigua hacienda Conde de las Torres (por lo que se le conocia también con dicho nombre). En la actualidad el sitio se ubica a la altura de la cuadra 27 de la avenida República Argentina en los terrenos ocupados por los locales fabriles de "Textil Algodonera S.A." y "Amortiguadores Gabriel" en la urbanización Industrial Wiese y al noroeste del complejo Maranga (Altamirano et alii 2001; Ericksen 1951; Shady 1982) (Fig. 1).

(1) La primera referencia del sitio se atribuye al Monseñor Pedro Villar Córdova, pionero de la arqueologia de Lima, que lo denomina "Macat" y lo ubica en terrenos de las haciendas Conde de la Vega y Mirones (Villar Córdoba 1984 [1935]). Al proyectarse la urbanización de las tierras de la hacienda en la década del 40 se inicia la destrucción del complejo arqueológico. Ante su inminente desaparición, el Patronato Nacional de Arqueologia dispone la realización de excavaciones de salvamento, las que se inician el 21 de noviembre de 1944 bajo la dirección de Julio C. Tello. En dichas excavaciones participaron Julio Espejo Nuñez, Toribio Mejia Xesspe, Cirilo Huapaya y Marino González (Narvaes 2002). 


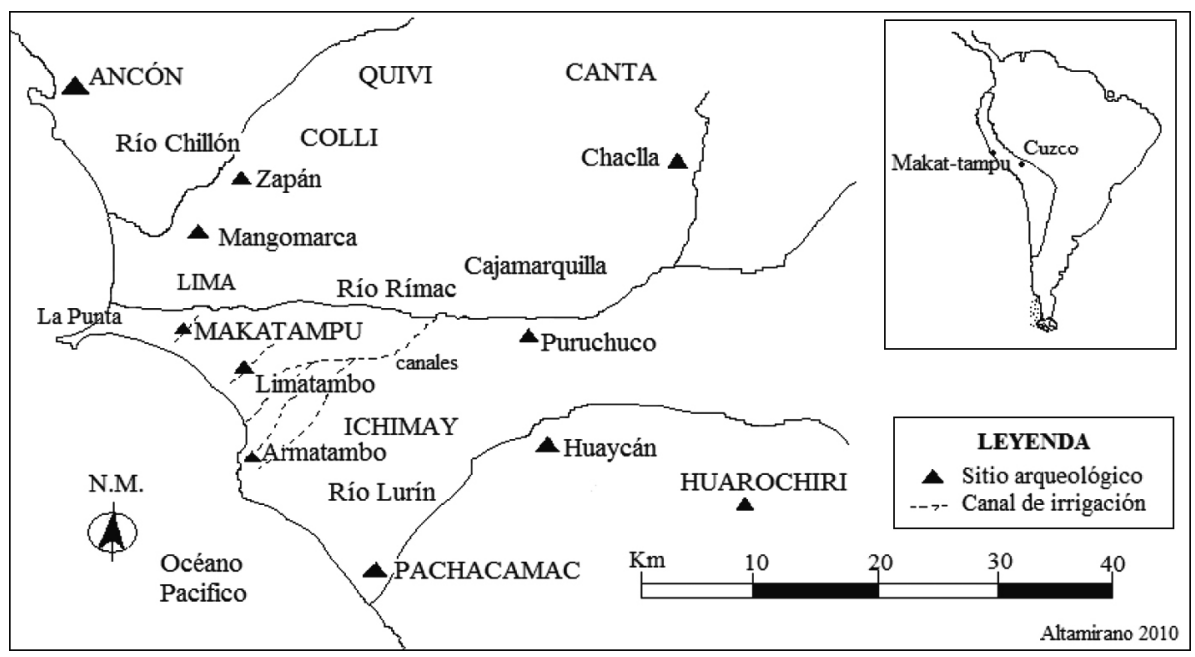

Fig. 1. Localización de Makatampu en el valle del Rimac, Lima, durante el imperio Inca.

El sitio, compuesto de tres sectores, fue construido de pequeños adobes de barro chamados adobitos y en los estratos superiores aparecen grandes bloques de tierra conocidos como adobón. El sector 1 era un monticulo que tenía la altura de 3 a $4 \mathrm{~m}$ y el montículo 2 entre 2,50 y 3,50 m. El extenso cementerio arqueológico corresponde al sector 3 donde se recuperaron alrededor de 800 enterramientos humanos, en forma de fardos con abundante relleno cultural, cantos rodados, grava y arena, perteneciendo a diversos períodos culturales desde Maranga o Lima, Ichmay hasta la época incaica, siendo en su mayoría entierros intrusivos de periodos tardios (Bazán 1990).

A unos $250 \mathrm{~m}$ al norte del sitio, según la foto aérea, se observa un gran camino delimitado por altos muros de adobones con una acequia al costado y con dirección SurEste/Nor-Oeste. Dicho camino se conectaba con varias chacras de esa zona; 100 metros más hacia el NO se encontraba con el canal de La Legua, uno de los principales canales de irrigación del valle y del cual salian varios ramales secundarios, dos de estas acequias conducian aguas a MT y de alli a Maranga y Magdalena del Mar (Fig. 2).

El valle del Rimac, que engloba en su porción baja a la ciudad de Lima, fue ocupado desde el período precerámico por diversas sociedades simples de pescadores y recolectores que se asentaron en los vecinos valles de Chillón y Chilca como Ancón, Chivateros, El

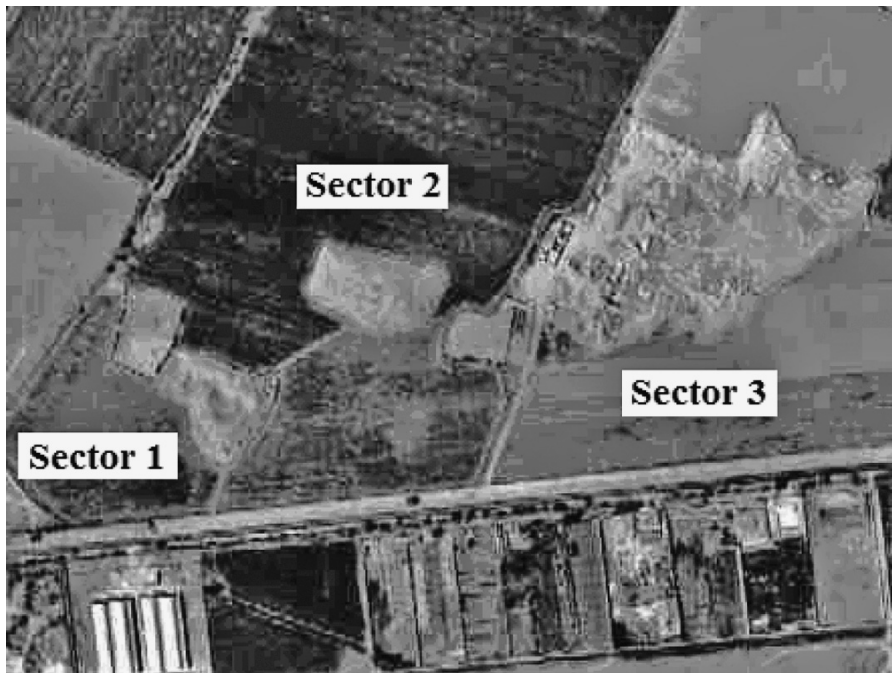

Fig. 2. El conjunto arqueológico de Makatampu en 1944 antes de su total destrucción, aerofoto del Servicio Aerofográfico Nacional, nótese la avenida Argentina que va al Callao. Foto cortesía del arqueólogo Lizardo Tavera, enviado en 2008. 
Paraiso y Paloma. Durante el periodo Formativo y Horizonte Chavin (entre 1.800-200 a.C.), la población se incrementó, lo que permitió la construcción de diversos templos en forma de "U" como Chocas, Huacoy, Coto-Coto, Garagay, Cardal y Mina Perdida, entre otros (Burger 1993; Williams 1971). Durante el periodo Intermedio Temprano (200 a.C.- 700 d.C.), el valle fue ocupado por la sociedad Lima o Maranga que construyó complejos canales hidráulicos y lo embelleció con campos de cultivo, templos de adobitos y aldeas de quincha con fina artesanía para el intercambio con la sierra a través de caminos y puentes transportados por recuas de llamas. Durante el Horizonte Medio (700-1.200 d.C.) surgieron las ciudadelas de Cajamarquilla y Pachacamac, permitiendo el dominio de la sociedad Wari, lo que dio origen a la sociedad Ichimay, los cuales vivieron hasta la época del imperio Inca (Bazán 1990, 1991; Ravines 1985). En el valle de Chillón, durante los periodos tardios, habian diferentes etnias como los Macas, Zapán, Colli y Quivi; en el valle de Lurin dominaban los Pachacamac/Ichimay y Huaycán de Cieneguilla, así como en la sierra de Lima vivian los Canta, Huarochiri y Yauyos (Bueno 1992, 1982; Huertas 1992).

En el siglo XVI, la ecologia del valle comprendia un extenso bosque de algorrobos, carrizos, chilcos, huarangos, lúcumos, molles, paltos y pacaes, entre otros, que llegaba hasta las inmediaciones de los cerros de Ate, Vitarte, El Agustino, Huachipa, Lurigancho y Comas, donde vivian venados de cola blanca (Odocoileus virginianus), llamas (Lama glama), perros (Canis familiaris), zorros (Pseudolopex sechurae), monos, pumas, inmensa variedad de aves, roedores, batracios, lagartijas y serpientes, entre otros. Además, los ayllus o marcas eran especialistas en agricultura y pesca con artesanía, ceramistas y cestería que administraban una compleja red de canales de irrigación, hechos de barro y cantos rodados, y en sus riberas crecian copiosamente el carrizo llamado por los ichmas de quincha (Rostworowski 1978). La importancia por el control del agua ultrapasaba los aspectos económicos y organizaban innumerables fiestas comunitarias en relación a las acequias donde se bebia abundante chicha, danzas, comidas e permitia la integración de las marcas. La cerámica Ichimay Tardía está caracterizada por tinajas con decoración de bandas blancas verticales o "pepinos", asa horizontal, ollas con cara-gollete blanca y negra y batracios en los bordes de ollas de cuello corto (Feltham y Eeckhout 2004) (Fig. 3).

A pesar del enorme avance en las investigaciones arqueológicas de la costa central, principalmente en el valle del Rimac, poco se habia publicado sobre el tema de la paleopatologia (Altamirano et al. 2006; Ericksen 1951; González Chávez 1968; Guillén 1994).

\section{El cráneo humano}

El cráneo, con el registro de 047 (C-27), AF-3927 y MAP-682 del MNAAH, se encuentra
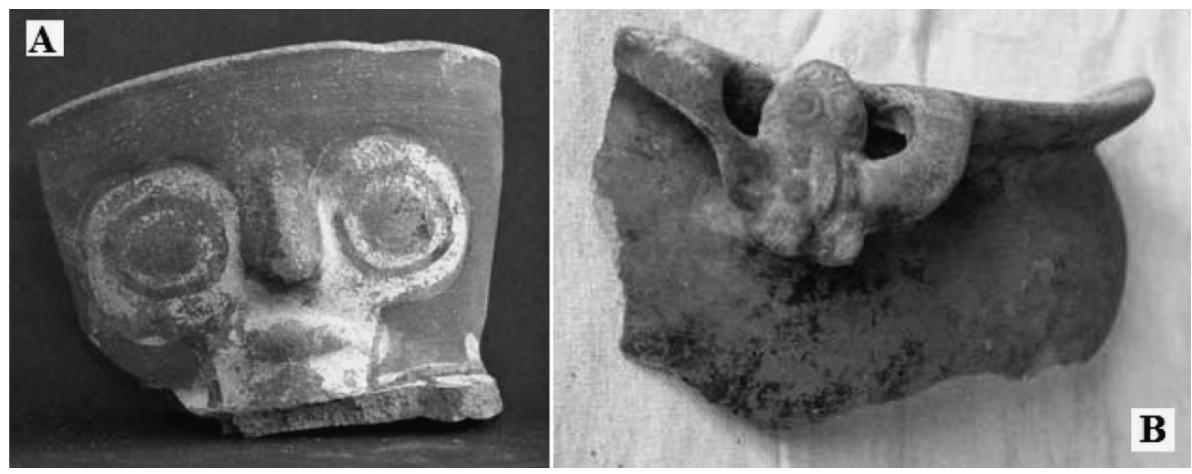

Fig. 3. Cerámica Ichimay Tardia procedente del valle del Rimac y Lurín. A: cerámica cara-gollete con el dios Ichimay; B: batracio en olla de cuello corto que simboliza la custodia de los canales (Feltham y Eeckhout 2004). 
en buen estado de conservación; de color blanco en la calota y amarillento en la base porque estuvo expuesto a la insolación por algún tiempo; tiene la forma de acrocráneo; presenta superficies delicadas y suaves con ligera deformación de la porción occipital izquierda; la cavidad ocular tiene forma cuadrangular con arcos superciliares cortantes y agudos; espina nasal poco elevada; hueso malar sin rugosidad; eminencias laterales del frontal notables; glabela ligeramente rugosa; dientes ausentes y perdidos post-mortem con algunos alvéolos dentarios obliterados y otros abiertos; arco zigomático delicado; los molares superiores de la arcada superior derecha in situ exhiben poco desgaste y están fracturados; mandibula poco rugosa, con obliteración de todos los molares pre-mortem; las apófisis mastoideas poco desarrolladas; cresta nucal ligeramente rugosa; sutura coronóide en proceso de obliteración; asimismo las suturas escamosa e lambdática están en proceso de fusión.

Esta descripción antropológica nos permite inferir que estamos ante una mujer robusta de unos 30-35 años de edad. La estimación de la edad fue establecida siguiendo el criterio de la sinostosis craneana (Comas 1976; Ubelaker 1989) y de la fusión de la sutura basilar (Weiss 1958). La aproximación del género fue establecida por las caracteristicas finas de la arcada dentaria y arcos superciliares, además de la glabela, las eminencias laterales del frontal y apófisis mastoideas poco desarrolladas (Ubelaker 1992)

Sobre la patologia ósea podemos describir que el hueso maxilar presenta una profunda fenda de 5-8 $\mathrm{mm}$ de ancho cuyo reborde es regular, profundo, a desnivel, de superficie suave y ausencia de vasculitis o reacción ósea en el paladar duro; esta fisura del paladar duro permite una ligación entre el canal oral y nasal; la espina nasal anterior está inclinada para el lado derecho; los alvéolos dentarios de los incisivos superiores también están en posición oblicua; la espina nasal posterior del hueso palatino remata en dos cúspides, formando una espina bifida, para la inserción de ligamentos linguales lo que habría servido para la formación de un cartilago y cerrar la fenda cuando el individuo estaba en vida. Es decir, la formación de este profundo pasaje comenzaba a la altura del incisivo superior izquierdo, recorriendo todo el hueso maxilar y se dirige al hueso palatino, a través del techo de la cavidad oral, terminando en una fenda inclinada en la parte posterior del cornete nasal inferior, siendo el reborde de forma recta, suave, homogéneo y sin reabsorción ósea (Fig. 4).

También exhibe un osteoma benigno en forma de gránulo de $8 \mathrm{~mm}$ de diámetro en la base de la orbita derecha, próximo al canal ocular; posee quistes radiculares de los premolares y molares superiores; exhibe hueso biastérico en la sutura lambdática, siendo el lado derecho mayor que el izquierdo. Sobre la alteración intencional del cráneo, esta se presenta en la

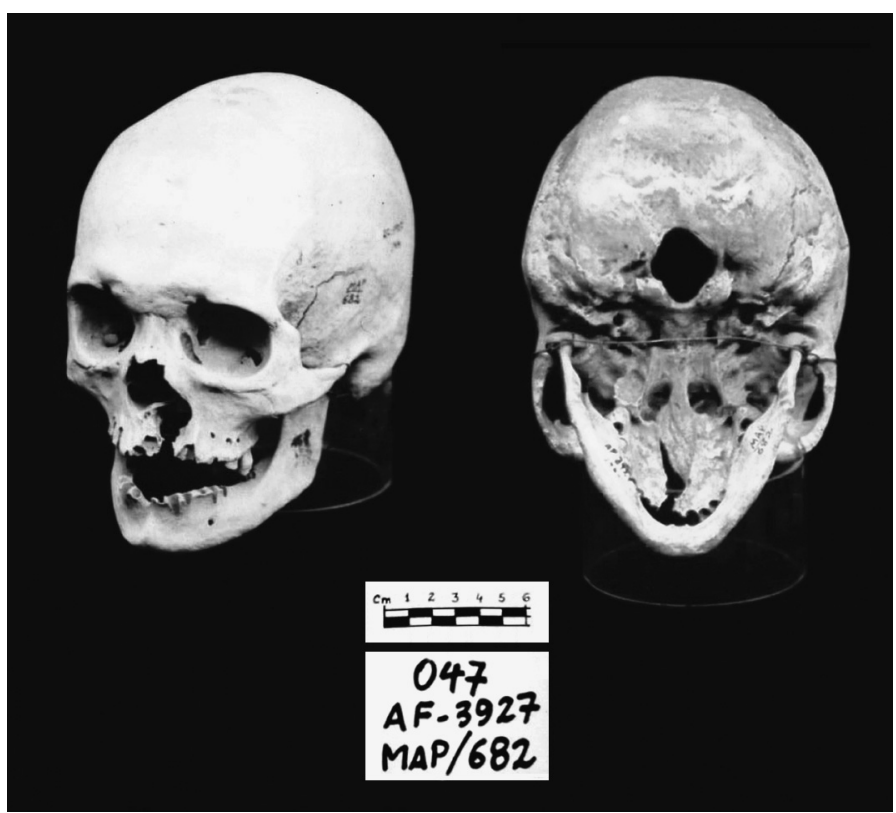

Fig. 4. Cráneo de Makatampu con "boca-de-lobo", caso C-47 (AF-3927; MAP 682), en la norma anterior (izquierda) y norma basal (derecha) observase la abertura entre las cavidades nasal y oral, sin reabsorción ósea. 
parte posterior izquierda que abarca la región astérica en forma vertical de 7 × $8 \mathrm{~cm}$, indicando pertenecer al grupo de la deformación fronto-occipital oblicua.

\section{Resultados}

1. Se trata de un individuo robusto do género femenino de unos 30-35 años de edad.

2. Exhibe la enfermedad genética de la fisura labio palatal del tipo "boca-de-lobo".

3. Las perdidas de los molares y premolares premortem por caries y los quistes radiculares indican ser una campesina de elevado consumo de carbohidratos.

4. El cráneo presenta una leve deformación cefálica del lado izquierdo de la región astérica indicando pertenecer al grupo de la deformación fronto-occipital oblicua.

5. Por la robustez del cráneo podemos inferir que era de una mujer de origen serrana.

\section{El diagnóstico diferencial}

Concerniente al diagnóstico diferencial de FLP, este puede ser subdivido en dos grandes grupos que causan lesiones liticas a nivel anatómico de las cavidades oral y nasal. Estos son las enfermedades infecciosas y el traumatismo (Bergsma 1978; Zimmerman y Kelley 1982; Ortner y Putschar 1985; Ortner 1992). Entre las enfermedades infecciosas que afectan a los huesos de la cara o esplacnocráneo tenemos la leishmaniasis mucosa (LM), paracoccidioidomicosis (PCM), hanseniasis, tuberculosis osteo-facial (TBC) y trepanomatosis (Pessoa y Barretto 1948; Ortner 1992; Rothschild et al. 1998; Altamirano 2000). También en raras ocasiones pueden comprometer este segmento osteofacial la esporotricosis, amebiasis y bartonelosis o verruga. Vale recordar que en el valle medio del Rimac, la bartonelosis es altamente endémica y milenaria, por tanto, también merece ser incluida en la diagnosis diferencial. Sin embargo, hasta la fecha no se han reportado casos comprometiendo la estructura osteo-facial (Allison et al. 1974).

Una caracteristica general de tales enfermedades infecciosas es la presencia de reacción ósea por las coinfecciones bacterianas o sobreagregada por Estafilococos aureus o por estreptococos, produciendo lesiones líticas o perforaciones redondeadas segregando líquidos muco-purulentos o muco-sanguinolentos, tanto en los cornetes nasales cuanto en la bóveda palatina. Sobre las lesiones liticas por LM se ha descrito que en determinados casos crónicos destruye el hueso palatino y maxilar en forma de arcos sinuosos con reacción ósea, afectando los bordes posteriores inferior y medio de los cornetes y los senos paranasales, también atingiendo las orbitas, el hueso maxilar, nasal y malar de la abertura periforme con abundante reacción ósea (Altamirano et al. 2001; Costa et al. 2009; Moreira 1994). Al comparar con nuestro caso, este carece de reacción y menos de lesión litica.

PCM, mal de Lutz o blastomicosis es una enfermedad autóctona de Sudamérica causada por el fungo Paracoccidioides brasiliensis que produce graves lesiones granulomatosas y ulceraciones de la piel, mucosas, ganglios linfáticos, pulmones y huesos. Siendo de baja frecuencia en los Andes Centrales y manifestándose casi exclusivamente en áreas rurales tanto tropical como subtropical. Puede causar lesiones liticas en las cavidades de las vías aéreas superiores de la porción anterior y comprometiendo a la bóveda palatina con reabsorción ósea, mas existiendo escasa información al respecto (Ortner 1992). El primer caso de PCM ocurrió en una momia del norte chileno. Se trata de una mujer de 56 años de edad que murió hacia 290 d.C. con lesiones pulmonares y renales (Allison et al. 1979). Tales autores sugieren que esta persona haya adquirido la enfermedad durante una expedición al área tropical. Sin embargo, nada refieren acerca de la destrucción de la región nasopalatina por PCM. Un segundo caso es el de un hombre negro de 47 años de edad, que vivió en los Estados Unidos, cuyo cráneo manifestó, a la altura del parietal izquierdo, una lesión lítica circular de $10 \mathrm{~mm}$ de diámetro. Alrededor de la lesión aparecen pequeños forámenes distribuidos irregularmente con frentes remodelados por reabsorción. Asimismo, se observan espículas ásperas $(1 \times 2 \mathrm{~mm}) \mathrm{de}$ hueso remodelado en el frente de la reabsorción 
ósea. Siendo el tamaño total de la lesión de 22 x $24 \mathrm{~mm}$ (Hershkovitz et al. 1998). En base a estas comparaciones vemos que PCM destruye el hueso craneal en forma circular con reabsorción ósea periosteal, en cambio, FLP no compromete los cornetes nasales ni el palatino, sino al hueso maxilar y careciendo de reabsorción ósea periosteal.

Para el DD de hanseniasis, Ortner (1992) expone un caso de lepra de un hombre de unos 20 años de edad, procedente del cementerio medieval de Chichester, Inglaterra, definiendo que esta compromete seriamente la estructura nasomaxilar con remodelación destructiva y profunda de la abertura periforme, el maxilar superior y la perdida de los incisivos superiores e inferiores. Sin embargo, en la norma facial, la lepra es rara y cuando aparece destruye la abertura sagital del maxilar con bordes irregulares, profundos, microporosidades por vasculitis y, por tanto, con fuerte reacción ósea periosteal. Otro caso es el de Makatampu, cráneo C-3 (femenino de 30-40 años de edad) que presenta criba orbitaria y una erosión difusa, externa, porosa y simétrica en el esplacnocráneo, neoformación ósea en los huesos frontal, malar y maxilar, siendo su DD de lepra lepromatosa (Altamirano 2000). Para discutir la osteopatología leprosa debemos tener en cuenta las siguientes nociones: casi la totalidad de estas lesiones se asientan en manos y pies; de 1,885 casos óseos de la época actual, se registraron 1,868 casos con lesiones en manos y pies $(99,0 \%)$, y 17 casos con lesiones extradistales $(0,9 \%)$; las lesiones óseas fuera de dichos segmentos son atipicas y raras; el elemento facial es afectado en relación a la madarosis y a la hipertrofia de los pabellones auriculares e independiente de orejeras (Pesce 1951). Al comparar con el cráneo de FLP no existe compatibilidad por la ausencia de neoformación ósea del maxilar ni intensa erosión externa. En el caso de lepra está no produce fenda. Por otro lado, los paleopatólogos indican que la lepra no estaba presente en el antiguo Perú, mas que ya tenía alta prevalencia en el siglo XVI, confundida con sifilis, leishmaniasis y bartonelosis y por eso fueron construidos los primeros leprocomios en 1550 (Pesce 1951). Sin embargo, este tema todavia no ha sido totalmente resuelto y el estudio de la antigüedad de la lepra en el Perú será tema de otro trabajo.

Para el DD de TBC comentamos que esta enfermedad ha ocasionado mucho debate entre los paleopatólogos en el curso de la segunda mitad del siglo XX en relación con la "artritis tuberculosa”. En MT no detectamos ningún el caso de TBC, en cambio, en Ancón podria ser el caso C-38 y en Huarochiri C-36. Estos cráneos presentan dos áreas de lesiones liticas. Una en el arco superciliar derecho del frontal, que se extiende desde la sutura nasofrontal derecha, alrededor de orbita derecha hasta la eminencia lateral frontal derecha $(45 \times 33 \mathrm{~mm})$ y otra en el occipital lado izquierdo ( $30 \times 26$ $\mathrm{mm}$ ) próximo a la sutura lambdática. El reborde de la lesión es irregular de aspecto gomoso, poroso, irregular y neoformación ósea. Esta superficie craneal expone escarificación, sin perforación total y con reabsorción ósea (Altamirano 2000). Siendo diferente de FLP por el tipo de reborde regular y sin reabsorción ósea. En el vocabulario quechua se designa con la voz Chaque-oncoy, Chullu-oncoy o sucyay-oncoy (Lastres y Cabieses 1959). Esta infección afecta principalmente a la espina dorsal, denominada Mal de Pott, destruyendo los cuerpos de las vértebras torácicas y lumbares, formando lesiones liticas, kyposis y expandiéndose luego a las costillas, esternón, clavicula y la cadera psoas - y es causada por el bacilo Mycobacterium tuberculosis (Moodie 1923). Siendo la columna vertebral, el área más común de infección, principalmente la región toracolumbar y causando lesiones liticas del cuerpo vertebral anterior (Ubelaker 1992). Además, su DD parece ser más próximo a osteomielitis piogénica y blastomicosis que a FLP.

Ortner (1992) describe un cráneo masculino de 15 años de edad que tuvo TBC desde los 5 años. Observó que estaba comprometida la estructura nasomaxilar, destruyendo los huesos nasal, cornetes, septum nasal, maxilar y paladar. Además, afectó la dentición total superior y cuyos alvéolos habian obliterado. La pieza ósea presenta en la cavidad nasal y la oral severas lesiones sin reacción ósea periosteal con bordes irregulares. Este caso se encuentra en el Museo 
de Patologia del Royal College of Surgeons of Edinburgh, Escocia. Actualmente, las historias clinicas reportan que la TBC esqueletal se manifiesta en aproximadamente $1 \%$ de todos los casos, en cambio, en el pasado, según Zimmerman y Kelley (1982) durante la era preantibiótica, la prevalencia era alta entre $5-7 \%$. En el antiguo Perú ocasionaba múltiples problemas en la salud pública y arrasaba con aldeas enteras junto con la neumonía (Allison, Mendoza y Pezzia 1973). El primer caso arqueológico bien documentado fue una momia Wari de 8 años de edad, que vivió hacia 700 d.C. El infante murió de infección pulmonar, tuberculosis de hígado, riñón, pericarditis y absceso del psoas con el mal de Pott en las vértebras lumbares. El método empleado por Allison se basa en acid-fast bacilli. Luego fueron identificados más de una docena de casos tanto en el tejido óseo como el tejido blando (Allison et al. 1981) y en otra momia Nasca del Horizonte Medio por Lombardi (1992). ${ }^{2}$

Comentamos que el área urbano de Lima, también denominado "la ciudad de los tísicos" en la época Colonial, mantiene una humedad elevada en invierno $(>90 \%)$ produciendo diversos trastornos bronco pulmonares, tos, catarro y alta prevalencia de TBC. Hasta la década de los 60 se recomendaba a los enfermos de TBC viajar a climas secos para su lenta curación, tanto a Jauja como a los valles cálidos de Huarochiri y Canta. Por tanto, existe notable diferencia patológica entre TBC craneal y FLP. Es posible admitir que en diversos casos la FLP haya condicionado a la invasión del Mycobacterium tuberculosis en el clima húmedo de Lima.

(2) En San Pedro de Atacama, norte de Chile, la investigación de las pneumopatias en la serie Solcor-3, durante el Horizonte Tiwanaku, acusó la presencia de procesos activos en el esqueleto de la caja torácica (costillas, escápula, esternón y vértebras) que posibilitó la muerte de algunos individuos. Entre los casos detectados se observó individuos con edad superior a los 30 años: 134 individuos de Solcor-3 y 31 esqueletos de Quitor-6 (10-15\%) con periostitis costal de lesiones activas por pneumopatias en área de condiciones endémicas (Prat et al. 2003). Sin embargo, no se menciona lesiones liticas en el cráneo.
Para el DD de la trepanomatosis sabemos que esta es una designación genérica a un conjunto de enfermedades infecciosas producidas por espiroquetas de la familia Treponema y su principal forma de transmisión es el contacto sexual. ${ }^{3}$ En el antiguo Perú se conocía como Huanti y era una cepa semejante a la buba. Producen graves lesiones granulomatosas y ulceraciones de la piel, mucosas, ganglios linfáticos, arteria aorta, nervios y huesos. En el caso de la sifilis endémica, las lesiones óseas son severas causando profunda lesión litica de forma circular u oval, tanto en la cavidad oral cuanto en la nasal con intensa reabsorción ósea (Valdivia 1988).

Ortner y Putschar (1985) estudiaron 10 cráneos del sitio arqueológico Norris Farm, Illinois, encontrando un patrón paleopatológico concerniente a caracteristicas de treponematosis con severa destrucción de la región nasopalatina. En esqueletos de momias peruanas el patrón patológico de la sifilis congénita en el periodo terciario es la destrucción gomosa del hueso nasal, frontal y parietal, de bordes irregulares y la periostitis de huesos largos, siendo el signo patognomónico la silla de montar en el hueso nasal (Tello 1909; Williams 1932; Weiss 1984). Asimismo, Valdivia (1985), estudió un cráneo sifilitico procedente de Ancón, tratase de un hombre de 44 años de edad. La arcada dentaria presenta reabsorción ósea asimétrica, con pérdida prematura de las piezas dentarias, ausencia de incisivos centrales formando un diastema y anodoncia parcial de los laterales. Este cráneo registra una extensa perforación naso-palatina, de forma oval de $3 \mathrm{x}$ $2 \mathrm{~cm}$, con su eje mayor en dirección antero-

(3) Las manifestaciones en la especie humana se subdividen en cuatro modalidades: pinta o pian, infección exclusivamente cutánea que causa decoloración de la piel; buba o framboesia, infección con manifestación cutáneo-mucosa en forma de tumoraciones y ulceraciones, que puede comprometer gravemente los huesos; sifilis endémica, manifestación orogenital que causa alguna lesión ósea; y sifilis venérea, forma cutáneo-mucosa, de transmisión exclusivamente sexual que puede manifestarse también de forma congénita, por la contaminación del neonato por la madre enferma y afecta severamente al esqueleto (Mendonça de Souza 1999). 
posterior. La nariz es tipica de silla de montar con su borde inferior dentado en forma de gotera, dando un aspecto de lavado. Además, las alas del esfenoides y las apófisis mastoideas no han sido desarrolladas en relación al cráneo. Incluso, presenta hiperostosis generalizada, siendo más acentuada en la parte medioizquierdo del hueso frontal. Asimismo, este investigador refuerza que la sifilis congénita o venérea produce lesiones en el cráneo, huesos faciales, perforación del paladar, del tabique nasal, hipoplasia del maxilar, incisivos con sindrome de Hutchinson, nódulos de schmorl etc. De 4,400 casos de sifilis terciaria, 229 casos exponen lesiones del esqueleto nasal que representa el 5,2\% (Valdivia 1988: 396). Así, el DD entre FLP y sifilis revela que esta última afecta severamente el paladar y maxilar formando lesiones liticas y fosas ovales profundas de reborde fino con reacción ósea periosteal (Powell y Cook 2005; Williams 1932), en cambio, FLP no exhibe lesiones liticas, tampoco posee reborde gomoso, ni destruye el borde posterior del hueso palatino y menos produce reacción periosteal o vasculitis.

El DD de traumatismo osteofacial causado por el impacto de golpes en las cavidades oral y nasal produce fracturas, rajaduras y microfracturas dando como consecuencia esquirlas, fragmentos del periostio de forma recta e fina observable en los casos de muerte por violencia. Asimismo, en individuos curados aparecen ligeras reacciones periosteales formando callos óseos posttraumáticos y algunos hasta complicaciones profundas de los senos paranasales causando osteomielitis (Roca 1953; Ubelaker 1989; Lessa et al. 2006). En la serie de Makatampu, Altamirano et al. (2006) indicó que 11 individuos tienen traumatismos principalmente en la región nasofrontal, representando el 35,5\% de la muestra, de los cuales nueve son hombres y dos mujeres. También en Ancón, Huarochiri, Chilca y Zapán encontramos casos de trauma nasal. Dos ejemplos ilustran la frecuencia de golpear esta región. El Caso C-39 (Reg. 078) procedente de Ancón y el C-44 de Zapán. En el primer caso observamos dilatación de los canales lacrimales e infección profunda del seno frontal derecho e izquierdo con lesión litica oval de $8 \times 5 \mathrm{~mm}$ para el drenaje de la infección, con leve reabsorción ósea periosteal y un crecimiento anormal y rugoso del hueso lacrimal derecho. La sutura nasofrontal está fuertemente obliterado y en depresión. Este porcentaje confirma en parte la descripción de Ericksen (1951), revelando que el 77,7\% de la misma muestra tenía trauma. En el DD con el caso de FLP podemos percibir la ausencia de callos óseos, microfracturas y esquirlas, sino una extensa fenda paralela que alcanza el hueso palatino.

\section{Discusión}

Desde inicios del siglo XX hasta la década de los 80 , la etiología de esta patología generaba intensas polémicas que se alineaban en tres tipos de causas: ambiento-nutricionales, infectocontagiosas y culturales-hereditarias. Asi en los congresos de labio leporino no existia una sola causa determinante (Munizaga 1992; Weiss 1984; Zimmerman y Kelley 1982). Hoy con el avance de la biologia molecular, las investigaciones biomédicas se orientan a la causa culturalgenética, la cual está interrelacionada con las diversas informaciones genéticas de cuño sindrómico y no sindrómico heredadas de los padres y condicionadas por los factores ambientales o geográficos y, sobretodo, culturales (Palomino et al. 2000; Palomino et al. 1992; Winter 1997).

En la literatura paleopatológica sudamericana no existian trabajos concernientes a la FLP, comúnmente llamado de labio leporino y su presencia en la antigüedad estaba refrendada solamente por la cerámica antropomorfa o huacos de la sociedad Mochica, siglos I-VII d.C. Sin embargo, esta evidencia indirecta no era suficiente para la interpretación arqueológica del labio leporino y menos para entender su causa en el contexto social andino. A continuación iremos a discutir las hipótesis centrales de este trabajo.

\section{Hipótesis de los casamientos endogámicos}

Durante el imperio de los Incas, los pueblos andinos se organizaban a través de ayllus o familias consanguineas ocurriendo al interior de las comunidades casamientos 
endogámicos para fortalecer al grupo social tanto en las llactas o ciudades como en las marcas o campos (Cobo 1964 [1653]; Espinoza 1990; Rostworowski 1986, 1992). ${ }^{4}$ Por este motivo nuestra hipótesis de trabajo propone que debido al elevado número de casamientos endogámicos y a la carga genética de individuos portadores no sindrómicos habrian condicionado al nacimiento de bebés con labios leporinos, FLP y otras enfermedades congénitas. Este presupuesto está basado de cuatro tipos de evidencias asociadas tales como el espacio funerario/contextual, la información etnohistórica, la cerámica Mochica y la antropologia cultural/ lingüistica. Veamos cada uno de ellos.

El espacio funerario costeño, compuesto de cementerios y huacas, posee lugares donde se depositaron los difuntos de un mismo ayllu durante varias generaciones y/o disturbadas por enterramientos de otros ayllus llamados "intrusivos". En el caso de Makatampu consideramos que eran grupos endogámicos porque ellos organizaban la veneración de sus difuntos que eran conservados en fardos o momias. $\mathrm{O}$ sea, los antepasados o mallquis eran bien custodiados y transportados en procesión durante las fiestas para legitimar la jurisdicción y el dominio geográfico de su territorio. Este fenómeno cultural provenía desde Lima Tardio, Nieveria, Ichimay Inicial, Medio y Tardio, este último corresponde al periodo Inca. Ellos enterraban sus difuntos con envoltorios de tejidos de algodón simple de color marrón, unos de cuerpo flexionado y otros extendidos con cerámica Ichimay-Inca como en Armatambo y Limatambo. Por otro lado, también había entierros "intrusivos" que servian para legiti-

(4) En Pumpu, ciudad inca de la sierra de Pasco y Junin, en la región del Chinchaysuyu, los casamientos de los pastores de alpacas y agricultores de alturas eran a través de danzas de las parejas en la plaza central de la llacta. Una de las más solemnes danzas para el casamiento era la de la titahuaraca donde los novios danzaban sosteniendo esta inmensa soga colorida (titahuaraca) que tenia la cabeza de una serpiente anaconda. Los jóvenes danzantes eran de los ayllus de Huayllay y Chinchaycocha. Las mujeres tocaban la tinya o tambor y los hombres la zampoña o antara. Es decir, seguian el patrón rigido del casamiento endogámico (Altamirano 1993). mar el control territorial y cultural del valle por los grupos foráneos. Los casi 800 entierros procedentes de estos periodos culturales nos hace pensar la densidad demográfica del sitio y de ayllus ligados a actividades agricolas. Un serio problema es la definición del contexto funerario del cráneo bajo estudio, ya que las fichas de campo y el esqueleto post-craneal fueron perdidas. Sin embargo, creemos que son de la ocupación inca por el tipo de deformación craneana foránea, la cerámica Ichimay Tardia y formar parte del grupo de entierros intrusivos.

La etnohistoria nos revela que las antiguas poblaciones humanas del valle del Rimac controlaban una serie de canales de irrigación, considerados ríos, como los de Maranga, Surco, Legua o Guala y Huatica que se extendian por vastas regiones de las marcas de Lima. Durante el Horizonte Tardio, el valle estaba siendo reorganizado politicamente en comunidades llamadas pachacas que comprendia a los señorios de Armatambo, Carabayllo, Chucuito, Herbay, Huancho, Limatambo, Lati, Vitarte, Maranga, Ñaña y Puruchuco, que anteriormente formaban diversas marcas o ayllus bajo el control politico de los Ichimay (Bueno 1978; Rostworowski 1978). Al parecer cada ayllu controlaba una parte de los canales que pasaba por sus tierras. Además, en el valle los agricultores trocaban sus productos con los pescadores, cazadores, pastores y artesanos, a través de comerciantes que estaban al servicio de un señor (Ramirez-Horton 1982). ${ }^{5}$

Rotworowski (1992) afirma que ellos se desplazaban a los valles interandinos, llamados lomas o chaupiyungas, donde tenían campos de cultivo, corrales, chozas y criaban llamas. Ellos sembraban maiz (Zea mays), frijol (Fasciolus vulgaris), coca (Erythroxylon novogranatense, E. coca), aji (Capsicum sp.), zapallo (Canavalia pepo),

(5) En el periodo Inca, el valle bajo del Rímac albergaba unos 150,000 habitantes asentados próximos a los ríos y las acequias donde construyeron sus casas de adobón con techos de junco y carrizo o quincha. Todavia hasta mediados del siglo XX se usaban los caminos y canales precolombinos, los cuales fueron descritos detalladamente por Ephraim Squier en 1885 y Ernest Middendorf en 1894 (Rowe 1946; Rostwoworski 1978). 
papas (Solanum tuberosum), camote (Hypomoea batata) y achira (Canna edulis), entre otros productos. Así la pérdida de molares y premolares por caries dentarias del cráneo estudiado confirma el elevado consumo de carbohidratos (Altamirano 2000). Las aguas eran administradas desde sus nacientes o bocatomas en el valle medio, la distribución, limpieza, reparación y horario marcado para conducirlas de una acequia a otra, y durante todo el año practican diversas fiestas comunales y cíclicas. La importancia de los canales superaba el aspecto económico y muchos enterramientos humanos fueron depositados en fardos dentro de estas estructuras hidráulicas como los hallados en Maranga, en el campus de la Pontificia Universidad Católica del Perú y en el Parque de las Leyendas.

La hipótesis de que esta población agricola era emigrante mitmaccuna procedente de la sierra de Lima donde vivian los Yaucha y los Chacalla, fue propuesta en 1990 (Espinoza 1990), la cual fue comprobada cuando se identificaron cinco casos de LM debido al intenso movimiento a las áreas endémicas de leishmaniasis y bartonelosis en el valle medio del Rímac (Altamirano et al. 2001). Además, durante los periodos tardios habia una vieja rivalidad politica serrana entre los Cantas y los Yauyos por el dominio de las tierras bajas del Rimac que se intensificó durante el imperio Inca cuando fueron conquistados los señorios de Ichimay (Rostworowski 1978). ${ }^{6}$ Así, los incas para administrar el valle instalaron cinco guarniciones o tambos, siendo Makatampu uno de aquellos centros. Seguidamente millares de hombres con sus familias fueron trasladados al valle del Rimac y convertidos en mitmaq para la ejecución de las labores agricolas. Estudios craneométricos de MT indican la afinidad antropológica con los de la sierra de Lima y los hombres de Macas del valle del Chillón

(6) Cuando los Incas conquistaron los valles del Rimac, Chillón y Lurin al mando de Tupac Yupanqui, por vuelta de 1470, introdujeron mitmaq procedentes de la sierra de Lima, principalmente de Yauyos y Canta (Espinoza 1990; Makowski 2003). En el siglo XVI hubo intensos conflictos por las tierras de los cocales del valle medio (Rostworowski 1987).
(Altamirano 2000; Ericksen 1951), además el cráneo estudiado posee deformación cefálica circular oblicua propia de la región de Canta, arriba del río Chillón, sierra de Lima (Villar Córdoba 1960). Estos datos confirman que serian pueblos introducidos de la sierra que llegaron al valle del Rimac a través del valle del Chillón.

Por tanto, los agricultores de MT formaron parte de la esfera administrativa Inca para cultivar las tierras del sol y del estado, anteriormente propiedades de los Ichimay (Bueno 1992; Rostworowski 1978). Por su vez, cada pachaca era relativamente autosuficiente, tenía su propio centro público y templo o huaca, donde se realizaban diversas actividades administrativas, económicas y religiosas. Cada sector del valle tenía un canal principal y otros subsidiarios bajo el control del "Señor de Pachaca" con su correspondiente población campesina (Shady 1982). Los jefes o curacas locales rendian tributo Taulichusco, que era el "Señor del valle", con residencia en Pachacamac y administraba la provincia de Lima que tenía cinco tambos.

El estudio paleopatológico confirma que estas poblaciones sufrieron diversos trastornos traumáticos ocasionados por las "batallas rituales" entre los ayllus antiguos versus los nuevos durante las fiestas religiosas del culto y limpieza de los canales que terminaba en constante violencia, produciendo heridos y/o muerte por lesiones encéfalocraneanos a nivel nasofrontal, fracturas nasales osificadas y trepanaciones en cráneos de individuos masculinos jóvenes y adulto-jóvenes (Altamirano et al. 2006). Por lo expuesto se desprende que el control de los canales producía estrés entre los ayllus Ichimay versus los ayllus foráneos (yacuaz), estrechándose las relaciones de grupo a través de matrimonios endogámicos de las marcas o pachacas y se desplazaban a Pachacamac para resolver sus conflictos de aguas y tierras, llevando y depositando ofrendas en los templos para obtener la bendición de los oráculos. Un aspecto cultural importante de esta población eran las fiestas religiosas en honra a Pachacamac y la limpieza de los canales. En estas fiestas habia abundante chicha o acca, se concentraban 
los jóvenes, formándose las primeras relaciones de las parejas antes del casamiento y era común la práctica del servinacuy. ${ }^{7}$ Así estos casamientos endogámicos darian condiciones altamente favorables para el nacimiento de bebés con labio leporino.

Para reforzar esta discusión indicamos que los mochicas ya conocían la FLP entre los siglos III al V d.C. Ellos vivieron en la costa norte del Perú mil años antes de los Incas y habian percibido esta patologia entre los campesinos y la representaron en la cerámica antropomorfa o huacos, en la cual se observa la lesión frecuentemente en el lado izquierdo del labio superior observándose los dientes incisivos y la encia. Eran individuos de estatus social elevado, tenían tocados diferentes que representaban a sus ayllus agrícolas, adoraban al dios Aia-Paec y practicaban el culto a las aguas y a la fertilidad (Carod-Artal et al. 2006; Donnan 1978; Lastres y Cabieses 1959; Verano y Lombardi 1999; Weiss 1984). Consideramos que los símbolos de los tocados y aretes pueden ser indicadores del grupo social y la variedad de lesiones labiales pueden indicarnos su frecuencia en la costa norte debido a la práctica de la endogamia. Sin embargo, el estudio iconográfico de FLP en la cerámica Mochica será motivo para otro trabajo de investigación (Fig. 5).

En la sierra de Lima todavia existe el termino quechua qqoqya que significa labio leporino y se extiende por toda la sierra central y sur (Gonzales Holguin 1608). También en el altiplano de Bolivia, Lastres registró el vocablo aymará de santi (Lastres 1951; Lastres et al. 1959). Además Valdivia (1988) añadió en la sierra de Lima el vocablo quechua de parálisis facial llamado de wakra sipri o waqra simi = boca torcida o boca lesionada. Estos antiguos pobladores atribuian que la causa de la qqoqya o labio leporino era la marca de los dioses, principalmente de la divinidad Illapa, un dios trino compuesto por el rayo, relámpago y

(7) El servinacuy era una practica cultural andina que ocurria al interior de cada ayllu, lo que permitia la convivencia de las parejas por un año, por lo general la relación era un éxito, sucediendo los casamientos en masa anualmente y durante las fiestas oficiales (Espinoza 1990).

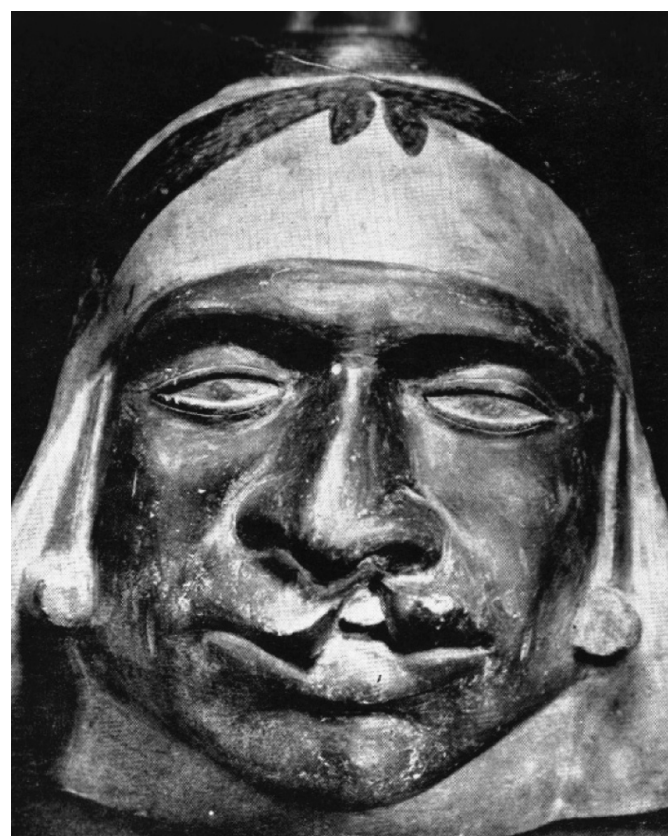

Fig. 5. Un caso indirecto de labio leporino procedente de la costa norte peruana, sociedad Moche, fase IV, elaborado entre los siglos IV-VI d.C., periodo Intermedio Temprano (Lastres y Cabieses 1959, fig. 22; Pieza del Museo de Ciencias de la Salud de Lima).

trueno, adorado por los incas desde Cajamarca hasta el Cusco (Espinoza 1990; Lastres 1951). ${ }^{8}$ Los bebés que nacian con labio leporino, en la mayoria - hijos de brujos o curanderos estaban destinados a ser los futuros curanderos de las comunidades.

El padre español Francisco de Ávila (1975 [1598]) menciona que uno de los principales dioses de Huarochiri y Yauyos, llamado Namsapa, hijo de Illapa y Pariacaca, poseia tres enfermedades asociadas: leishmaniasis o $u t a$, labio leporino o qqoqya y bocio o coto. Era un dios poderoso, considerado hediondo e humilde, de vestimenta simple, conducía y protegia los canales de

(8) Igualmente Tello (1967: 18) y Antúnez de Mayolo (1981) apuntan que los indios de Yauyos y Huarochiri consideraban que cuando nacia un bebé con labio leporino o con polidactilismo era la marca de Illapa o descendiente del rayo y estaba dotado de poderes mágicos para la reproducción del ganado y la multiplicación de las cosechas. Esto también se extendía para las crías de alpacas y llamas con estas patologias. 
irrigación, y por eso, era venerado como transformador de las montañas y simbolizado por la honda o liwi (apud Weiss 1984). Siguiendo al mismo autor Ávila (1975 [1598]: 197), sobre las costumbres de los Checa (sierra de Lima), apunta que el niño o cria que naciese con seis dedos es denominado de ata, y al tercer año de edad se les hace el ritual del corte-pelo o esquila. En Sucyacancha y Tumna, Huarochiri, cuando nacen mellizos o curi se sacrificaban muchos venados luychu, comiéndose la carne en una ceremonia comunal. Si los mellizos eran de sexo opuesto era considerado señal de buen año, mas si eran del mismo sexo el augurio seria negativo. En este último caso se producia el corte-pelo de los padres y consecuente castigo durante un mes (Ávila 1975 [1598]: 145).

De estas citaciones se desprende que los habitantes de Huarochiri creian que la deformación de los bebés o guaguas tanto humanos cuanto camélidos, era una marca directa de los dioses de las montañas conduciéndose a un destino especial de elevado status sagrado. Muchos de ellos fueron sacrificados en tiempos de lluvias torrenciales, calamidades, terremotos o secas prolongadas para resolver el problema en el "otro mundo". En suma, el dios Illapa estaba simbolizado por las tres patologías indicadas en el rostro por lo que muchos hombres y mujeres de las comunidades de Huarochiri pasaron a mutilarse sus rostros y labios superiores (a veces con escarificaciones) en honra de la fe que tenían por aquella divinidad. Planteamos, además, que la presencia de FLP en el dios Illapa permite considerar su enorme antigüedad en Huarochiri, junto con la leishmaniasis y el bocio, comprobando el registro pictórico Mochica.

En sintesis, durante los periodos tardíos y la ocupación incaica, la densa populación humana del valle del Rimac compuesta por diversos ayllus o marcas, entre los antiguos Ichmas versus los introducidos mitmaq vivían en permanente competición por el control de los canales y las chacras, estas intensas rivalidades permitió el estrechamiento de los ayllus que defendian los matrimonios consanguineos para fortalecerse y así surgió el incremento de estrés que permitió el aumento de hiperostosis porótica y criba orbitaria en el valle con anemias y alta mortalidad de niños (Altamirano 1994) y violencia social. Por eso, la hipótesis de los casamientos endogámicos es un fuerte factor sociocultural para el nacimiento de bebés con labio leporino, FLP y otras enfermedades congénitas, al lado de constante violencia ritual.

\section{La hipótesis biomédica}

Esta segunda hipótesis de trabajo propone que algunas mujeres con menos de tres meses de gestación y que tuviesen algún pariente en su genealogia con labio leporino corrian un alto riesgo de tener hijos con esta malformación genética. En el caso de MT, ellas habrian estado participando de las fiestas comunitarias ingiriendo elevada cantidad de chicha y consumo de la hoja de coca, causando las modificaciones genéticas del embrión y surgiendo casos de FLP.

El labio leporino solo o asociado a FLP es una malformación congénita común en las poblaciones humanas y otras especies de mamiferos como consecuencia de disrupciones en los distintos mecanismos embriológicos que ocurren durante el proceso de desarrollo de la región máxilofacial (Zimmerman y Kelley 1982). ${ }^{9}$ Desde un punto de vista clínico, esta malformación puede ser parte de un sindrome. Numerosos sindromes pueden tener entre sus manifestaciones labio leporino, ya sea sindromes por aberraciones cromosómicas como por entidades monogénicas. Sin embargo, entre 50

(9) Durante el desarrollo y crecimiento prenatal de un individuo, ocurren una sucesión de eventos morfológicos, fisiológicos y bioquímicos altamente integrados y coordinados. Por ello cualquier interrupción o modificación de este patrón puede dar origen a malformaciones congénitas. El componente ambiental también tiene una gran importancia como causa de la FLP y la prevención de esta malformación se podria basar fundamentalmente en el control de este. Existen numerosos trabajos que prueban que fármacos, factores nutricionales, elementos físicos o psíquicos pueden afectar el normal desarrollo del paladar. Estos antecedentes han permitido catalogar a las fisuras faciales como malformaciones de origen multifactorial, con un componente genético aditivo poligénico (Minsal 2005). 
y $70 \%$ de las fisuras de labio con o sin fisura velopalatina que se presentan son de origen no sindrómico. Aunque generalmente estas malformaciones se presentan como única caracteristica, cuando existen malformaciones asociadas, estas afectan con mayor frecuencia a las extremidades, ojos (anoftalmia, microftalmia) y corazón. Por otra parte, el riesgo de asociación estaria correlacionado con la gravedad de la fisura (Ballew et al. 1993; Palomino et al. 2000).

Desde un punto de vista epidemiológico, existe una clara distribución racial en la susceptibilidad poblacional. La incidencia general estimada de labio leporino y FLP es de 1 en 1000 nacimientos vivos, aunque las poblaciones de origen negro exhiben menores tasas $(1: 2500)$ y las orientales las mayores (1:700), independientemente de la región geográfica de residencial. Estudios en poblaciones amerindias revelan también altas incidencias, posiblemente relacionadas con el origen oriental de estas poblaciones, pero también asociada a otros factores poblacionales como edad materna, consanguinidad, estrés y contaminantes ambientales entre otros (Amidei et al. 1994; Palomino et al. 1997).

Munizaga (1992) apuntó que el labio leporino es una embriopatia causada por gérmenes de enfermedades infecciosas que afectan a los embriones de las mujeres gestantes, dando lugar a las malformaciones congénitas de la población. Además, asevera que esta enfermedad no estaba presente en el litoral chileno durante las ocupaciones precolombinas y solamente apareció a partir del contacto español. Todo parece indicar que Munizaga desconocía el origen multifactorial de FLP, la paleopatologia de los huacos mochicas mencionado anteriormente y ya se le conocía con diversos nombres regionales: qqoqya y waqra simi en quechua, santi en aymará.

Jeffrey Murray (2002) formularan una hipótesis biomédica basada en el DNA del labio leporino. La investigación fue realizada en un par de gemelos idénticos nacidos en Bauru, São Paulo, de tres años de edad y uno de ellos presentaba la FLP. Concluyeron que el surgimiento de FLP en el niño patológico se debía a la mutación y ausencia del gen IRF6 del cromosoma
1. Además admite que este gen, en su forma correcta, controla la formación de la boca, dientes y labios, más cuando modificado, provoca rajaduras en la cavidad oral. Cerca del $70 \%$ de portadores de la mutación nacen con labio leporino o FLP. La anomalia se hace presente en uno de cada 700 recién nacidos, puede ser causada por uso de alcohol, cigarro o drogas durante la gestación. En el Hospital de Pesquisa y Rehabilitación de Lesiones LabioPalatinas de la Universidad de São Paulo, centro de referencia mundial, con más de 53 mil pacientes, ya fueron estudiados más de 150 pacientes con FLP. El gen está asociado a los sindromes de Van der Woude, el más común, y PPS, que causa deformaciones en la piel y genitales (Fig. 6).

Sampson (1997), con experiencia en los Estados Unidos, apunta que el uso de alcohol por las madres gestantes provoca el sindrome del alcohol fetal que envuelve alteraciones en el cráneo, rostro y otras malformaciones congénitas,

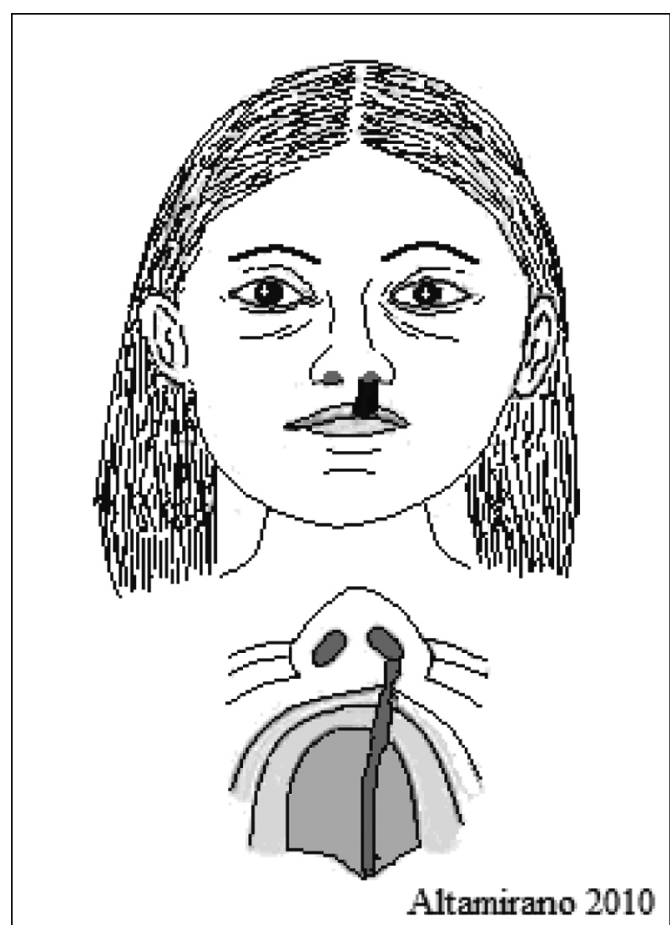

Fig. 6. Reconstrucción del rostro de la mujer de Makatampu y la extensión de la lesión con base al cráneo estudiado. 
además del retardo mental y déficit en el crecimiento. Doto Baú (2002) afirma que en el Brasil actual existe una gran carencia de estudios sobre epidemiologia de los efectos del alcohol en el feto. Sin embargo, se cree que el alcoholismo representa un serio problema de salud pública y está fuertemente ligada con determinados genes como el alelo Taq1A1 del receptor D2 y el alelo de siete repeticiones de VNTR en el tercer exon del gen receptor D4 de la dopamina que surge en relación al comportamiento de la persona.

El modelo de Murray (2002) y Sampson (1997) defienden que las madres con menos de 3 meses de gravidez y consumen altas cantidades de bebidas alcohólicas y drogas (hojas de coca, cocaina) modifican el gen del interferón IRF6 del cromosoma 1, produciendo alteraciones labiopalatinas. Sin embargo, la complejidad genética del embrión está condicionada por los antecedentes familiares portadores para la aparición de FLP. Por eso la hipótesis biomédica nos permitió discutir el caso de MT que habia sido descuidada por los paleopatólogos andinos. En suma, las fisuras palatales y labiopalatinas pueden ser sindrómicas, cuando están relacionadas a otras anomalias congénitas formando parte de los sindromes genéticos. Existen más de 200 tipos de sindromes genéticos, causadas por alteraciones cromosómicas o por mutaciones genéticas que incluyen a FLP. Mientras tanto, en la mayoria de los casos las fisuras son nosindrómicas, o sea, se presentan como una alteración aislada. La causa de esas fisuras es compleja y pueden estar relacionados a factores genéticos y/o ambientales. Entre los factores genéticos están las alteraciones cromosómicas y las mutaciones de uno o varios genes, los factores ambientales incluyen el uso de alcohol, drogas o coca para épocas arqueológicas, durante el primer trimestre de gestación. Sin embargo, la presencia de úvula bífida y osteoma en la base de la órbita derecha del cráneo bajo estudio son fuertes indicadores para incluirlo en el tipo sindrómico y por los casamientos endogámicos tan enraizado en la cultura andina.

Por otro lado, el presente estudio paleopatológico comprueba que los amerindios tienen una fuerte carga genética asiática (Amidei et al. 1994; Ballew et al. 1993; Palomino et al. 1997). En el Perú actual las regiones amazónicas y la sierra central como Ucayali, Loreto, Junin y Cerro de Pasco concentran altos indices de prevalencia de labio leporino debido a la continuidad de los casamientos endogámicos y uso de alcohol y drogas. Este estudio es pionero y nada sabemos sobre la paleopatologia ósea del labio leporino en periodos anteriores al imperio Inca. Esperamos que este estudio haya contribuido al entendimiento de un individuo con FLP que vivió en la prehistoria del valle bajo del Rimac.

\section{Agradecimientos}

Al Consejo Nacional de Pesquisa Brasileña (CNPq) que concedió una beca de estudios de doctorado (1996-2000) en la Escola Nacional de Saúde Pública (Fiocruz) y a la FAPERJ por la beca de profesor visitante ligado al Instituto de Pesquisa Clinica Evandro Chagas, Fiocruz, entre 2002-2004, Rio de Janeiro. A la Dra. Sheila Maria F. Mendonça de Souza por su valiosa enseñanza de la paleopatología y arqueologia brasileña y a la Dra. Raffaella Bianuci, paleopatóloga de la Universidad de Turin (Italia), por la lectura del texto final.

En Lima, a la Dra. Hilda Vidal Vidal, jefa del Departamento de Antropologia Fisica del Museo Nacional de Arqueologia, Antropologia e Historia del Perú de Pueblo Libre, Lima, que permitió la cristalización de este estudio y a la arqueóloga Elba Manrique de esa misma institución que dio apoyo logistico en los trámites burocráticos para el desarrollo de esta investigación. 
ALTAMIRANO ENCISO, A.J.; GARCÍA-ZAPATA, M.T.A. A case of palatal-lip fissure or "wolf-mouth" during the Inca Empire, Rimac Valley, Peru, XV-XVI centuries. Revista do Museu de Arqueologia e Etnologia, São Paulo, 20:361-380, 2010.

\begin{abstract}
The skull of a 30-35 years old woman showing a severe palatal lip fissure, focused in this article, was found at archaeological site of Makatampu, Rimac valley, central coast of Peru. The skull most likely belongs to a farmer who lived in highlands between the Late Ichimay period and the installation of the Inca Empire $\left(15^{\text {th }}\right.$ - $16^{\text {th }}$ centuries).

In our study, we were able to identify one case $(0.41 \%)$ of leporine lip out of 241 examined skulls. There are many controversies concerning the etiology of the leporine lip in Andean populations and two different hypotheses have been formulated. The former hypothesis, which is a biomedical one, indicate that the prevalence of the leporine lip in Andean populations was due to a genetic alteration caused by the abuse of alcohol and drugs during the official parties. The latter, based on ethno-historical and anthropological data, points out to the fact that ancient populations of central Peruvian coast were practicing endogamous marriages. Hence, endogamy would have determined an increased number of cases showing this malformation.

Even if only one pathological case has been reported in our study, we emphasize that the presence of the above disfiguring disease is well represented both in the Mochica culture's iconographical sources (e.g. the head pottery or huacos) and in the Andean philology. Taken all together, these data allow us to hypothesize that Andean populations showed higher incidence of leporine lip than shown by the paleopathological investigations.

Even if only one pathological case has been reported in our study, we emphasize that the presence of the above disfiguring disease is well represented both in the Mochica culture's iconographical sources (e.g. the head pottery or huacos) and in the Andean philology. Taken all together, these data allow us to hypothesize that Andean populations showed higher incidence of leporine lip than shown by the paleopathological investigations.
\end{abstract}

Keywords: Congenital paleopathology - Lip-palatal fissure - Incas Endogamous - Indians of Peru.

\title{
Referencias bibliográficas
}

ALLISON, M.J.

1974 Infectious diseases in Pre-columbian inhabitants of Peru. American Journal of Physical Anthropology, 41: 468.

1993 Leishmaniasis. In: Kiple, K.F. (Org.) The Cambridge world history of human disease. Cambridge, Cambridge University Press, cap. VIII: 832-4.

ALLISON, M.J.; MENDOZA, D.; PEZZIA, A.

1973 Documentation of a case of Tuberculosis in Pre-Columbian America. American Review of Respiratory Diseases, 107: 985-991.

ALLISON, M.J.; GERSZTEN, E.; MENDOZA, D.

1974 A case of Carrion's disease in associated with human sacrifice from the Huari culture of southern of Peru. American Journal of Physical Anthropology, 41: 295-320.

ALLISON, M.J.; GERSZTEN, J.E.; MUNIZAGA, J.; SANTORO, C.; MENDOZA, D.

1981 Tuberculosis in Pre-Columbian Andean 
population. In: Buikstra, J. (Ed.)

Prehistoric Tuberculosis in the Americas.

Northwestern University Archaeological

Program, Evanston, Illinois: 49-61.

ALTAMIRANO ENCISO, A.J.

1993 El levantamiento arquitectónico de la ciudad Inca de Pumpu, punas de Junin y Cerro de Pasco. Tesis de licenciado en arqueología, UNSMSM, Lima.

1994 Relación entre la hiperostosis porótica y anemias en las antiguas poblaciones humanas de la costa central. Magistri et doctores, UNMSM, Lima, 9: 17-20.

2000 Comprometiendo la estructura osteofacial de las poblaciones humanas del antiguo Perú por la Leishmaniasis Tegumentaria de forma mucosa. Tesis de doctor en salud pública, Rio de Janeiro, ENSP/Fiocruz, 213p. http://portalteses. icict.fiocruz.br/transf.php?script $=$ thes chap\& id $=00010804 \& \operatorname{lng}=$ pt\& $n r m=$ iso

ALTAMIRANO, A.J.; MOREIRA, J.; MARZOCHI, M.C.

2001 Lesión litica craniana por leishmaniasis en Makat-Tampu durante el imperio Inca, siglos XV-XVI, valle del bajo Rimac, Perú. Revista do Museu de Arqueologia e Etnologia, São Paulo, 11: 227-42.

ALTAMIRANO, A.J.; RAMOS, E.S.; NAVARRO, M.A.

2006 Political violence in the Inca empire: skeletal data from 15th - 16th centuries in the Rimac Valley, Peru. Paleopathology Newsletter, June, 134: 27-8.

AMIDEI R.L.; HAMMAN, R.F.; KASSEBAUM D.K.; MARSHALL, J.A.

1994 Birth prevalence of cleft lip and palate in Colorado by sex dist ribution, seasonality, race/ethnicity and geographic variation. Spec Care Dentist, 14: 233-40.

ANTÚNEZ DE MAYOLO, S.

1981 La nutrición en el antiguo Perú. Banco de Reserva del Perú, Oficina Numismática, Lima.

ÁVILA, F.

1975 Dioses y hombres de Huarochiri. 2a. Edición, ciudad de México DF. Siglo XXI [1598].

BALLEW, C.; BECKERMAN, S.; LIZARRALDE, R.

1993 High prevalence of cleft lip among the Bari Indians of western Venezuela. Cleft Palate-Craniofacial Journal, 30: 411-3.

BAZÁN, F.C.

1990 Arqueologia y etnohistoria de los períodos prehispánicos tardios de la costa central del Perú. Tesis para optar el titulo profesional de licenciado en arqueologia. UNMSM, Lima.

1991 Arqueologia de Lima. CREArte, Lima.

BERGSMA, D.

1978 Birth Defects Compendium. 2a ed. New York: Alan R. Liss.

BUENO MENDOZA, A.M.

1982 El antiguo valle de Pachacamac. Boletin de Lima, 24 (4): 10-29.

1978 El Señorio de Ichimay. Espacio, Lima, 1 (2): 64-71.

1992 Arqueologia de Huarochiri. In: Huarochiri ocho mil años de prehistoria. Tomo 1, Municipalidad de Santa Eulália de Acopaya, Huarochiri, Lima: 11-64.

BURGER, R.

1993 Emergencia de la civilización en los Andes. Lima, Universidad Nacional Mayor de San Marcos.

CAROD-ARTAL F.J.; VÁZQUEZ CABRERA, C.B.

2006 Malformaciones y parálisis faciales en la cerámica de las culturas precolombinas Moche y Lambayeque. Neurología, 21 (6): 297-303. http://www.scribd.com/doc/ 49711429/Lectura-2-Malformaciones-yParalisis-Facial-en-culturas-Precolombinas

COBO, B.

1964 Historia del Nuevo Mundo. Madrid: Biblioteca de Autores Españoles, vols. 91-92 [1653].

COCKBURN, A.

1988 Diseases of Mummies of Peru. In: Cockburn, A.; Cockburn , E. (Eds.) Mummies, Disease, and Ancient Cultures. Cambridge, Cambridge University Press: 135-174.

COMAS, J.

1976 Manual de Antropología Física. México: Universidad Autónoma de México, México.

COSTA, M.A.; MATHESON, C.; IACHETTA, L.; LLAGOSTERA, A.; APPENZELER, O.

2009 Ancient Leishmaniasis in a Highland Desert of Northern Chile. Plos One, September, 4 (9): 1-7.

DALTON, H.P.; ALLISON. M.; PEZZIA, A.

1976 The documentation of communicable diseases in Peruvian mummies. Medical College of Virginia Quarterly, 12 (2): 43-48.

DONNAN, CH.B.

1978 Moche Art of Peru. Precolumbian Symbolic Communication. Los Angeles, California: Museum of Cultural History, University of California.

DOTO BAU, C.E.

2002 Estado atual e perspectivas da genética e 
epidemiologia do alcoolismo. Ciência $\mathcal{E}$

Saúde Coletiva, Rio de Janeiro, 7 (1): 183-90.

ERICKSEN, M.F.

1951 A Preliminary report on Late period Crania from the Central Coast of Peru. Conferencias de Ciencias Antropológicas, Vol. I. Homenaje al IV Centenario de la UNMSM, Lima: 201-216.

ESPINOZA, W.S.

1990 Los Incas. Economia, Sociedad y Estado en la era del Tahuantinsuyo. Lima, Amaru Editores.

FELTHAM, J.; EECKHOUT, P.

2004 Hacia una definición del estilo Ychsma: aportes preliminares sobre la cerámica ychsma tardia de la Pirámide III de Pachacamac. Bulletin du Institut français d'Études Andines, 33 (3): 543-79.

GONZÁLES CHÁVEZ, L.

1968 Cráneos humanos procedentes del valle del Rimac: Makat-Tampu. Tesis de bachiller en arqueologia, UNSCH, Ayacucho.

GONZALES HOLGUIN, D.

1608 Vocabulario de la lengua general de todo el Perú llamada lengua qquichua. Lima: Imprenta San Marti.

GORLIN R.J.; COHEN JR., M.M.; LEVIN, L.S.

1990 Syndromes of the head and Neck. 3rd Ed. New York: Oxford Univ. Press.

GUILLEN, S.

1994 Excavaciones de entierros humanos en Villa El Salvador, Lima. Magistri et doctores, Lima, UNMSM, 9: 21-40.

HERSHKOVITZ, I.; ROTHSCHILD, B.M.; DUTOUR, O.; GREENWALD, C.

1998 Clues to Recognition of Fungal Origin of Lytic Skeletal Lesions. American Journal of Physical Anthropology, 106: 47-60.

HUERTAS, L.V.

1992 Aspectos de la historia de Huarochiri en los siglos XVI y XVII. In: Huarochiri ocho mil años de prehistoria. Tomo 1, Municipalidad de Santa Eulália de Acopaya, Huarochiri, Lima: 241-270.

LASTRES, J.B.

1943 Representaciones patológicas en la cerámica peruana. Revista del Museo Nacional, Lima, 2: 37-66.

1951 La Medicina en la Epoca Inca. Historia de la Medicina Peruana, tomo V (1). UNMSM, Lima.

LASTRES, J.B.; CABIESES, F.

1959 La Trepanación del cráneo en el antiguo
Perú. Anales de la Facultad de Medicina, UNMSM, Lima, 42 (3): 258-320.

LESSA, A.; MENDONÇA DE SOUZA, S.M.F.

2006 Broken noses for the gods: ritual battles in the Atacama Desert during the Tiwanaku period. Memórias do Instituto Oswaldo Cruz, Rio de Janeiro, 101 (Suppl. II): 133-138.

LOMBARDI, G.P.

1992 Autopsia de una momia Nasca: Estudio paleopatológico. Tesis de médicocirujano. Fac. Med. Alberto Hurtado. Universidad Peruana Cayetano Heredia, Lima, 59 p.

1994 La paleopatologia en el Perú. Magistri et doctores, Lima, UNMSM, 9: 12-13.

MAKOWSKI, K.H.

2003 Un tambo inca en el Valle medio de Lurin. LXI Congreso Internacional de Americanistas, Santiago, Chile. Resumen: 45.

MENDONÇA DE SOUZA, S.M.F.; REINHARD, K.J.; LESSA, A.

2008 Cranial deformation as the cause of death for child from the Chillon river valley, Peru. Chungara. Revista de Antropología Chilena, 40 (1): 41-53.

MENDONÇA DE SOUZA, S.M.F.; ARAUJO, A.J.G.; FERREIRA, L.F

1994 Saúde e doença em grupos indigenas préhistóricos do Brasil: Paleopatologia e Paleoparasitologia. In: Santos, R.V.; Coimbra Jr., C.E. (Eds.) Saúde e Povos Indigenas, Rio de Janeiro, Editorial Fiocruz: 21-42.

MENDONÇA DE SOUZA, S.M.F.

1999 Anemia e Adaptabilidade em um Grupo Costeiro Pré-Histórico: uma Hipótese Patocenótica. In: Tenório, M.C. (Org.) Pré-História da Terra Brasilis. UFRJ. Rio de Janeiro: 171-188.

MENEGOTTO. B.; SALZANO, F.

1991 Epidemiology of oral clefts in a large South American sample. Cleft Palate Craniofac Journal, 28: 373-6.

MINSAL

2005 Guía Clinica de Fisura Labiopalatina. Ministerio de Salud, $1^{\text {a }}$ Ed. Santiago. www.redsalud.gov.cl/archivos/.../ FisuraLabiopalatinaR_Mayo10.pdf

MOREIRA, J.S.

1994 Estudo da Laringite Leishmaniótica. Dissertação de mestrado. Departamento de Cirurgia; Pontificia Universidade Católica do Rio de Janeiro. 
MUNIZAGA, J.B.

1992 Antropologia física de los Andes del sur. In: Meggers, B.J. (Ed.) Prehistoria sudamericana, nuevas perspectivas. Washington, DC: Taraxacum: 65-75.

MURRAY, J.C.

2002 Gene/environment causes of cleft lip and/or palate. Clinical Genetic, 61: 248-56.

ORTNER, D.J.

1992 Skeletal Paleopathology: Probabilities, Possibilities and Impossibilities. In: Verano, J.W.; Ubelaker, D.H. (Eds.) Disease and Demography in the Americas. Washington, D.C.: editora Uaxactum: 5-14

NARVAES, J.J.L.

2002 El antiguo complejo arqueológico Makatampu. Boletin del Museo de Arqueología y Antropología de la UNMSM, No. 24, Lima: 3-6.

ORTNER, D.J.; PUTSCHAR, W.G.J.

1985 Identification of Pathological Condition in Human Skeleton Remains. Washington, DC: Smithsonian Institution Press.

PALOMINO, H.Z.; GUZMAN, E.A.; BLANCO, R.C.

2000 Recurrencia familiar de labio leporino con o sin fisura velopalatina de origen no sindrómico en poblaciones de Chile. Revista médica Chilena, Santiago, 128 (3): 33-36.

PALOMINO, H.M.; PALOMINO, H.; CAUVI, D.; BARTON, S.; CHAKRABORTY, R.

1997 Facial clefting and Amerindian admixture in populations of Santiago, Chile. American Journal of Human Biology, 99: 225-32.

PALOMINO, H.; PALOMINO, H.M.; GOYCOLEA, A.

1992 Correlación de la frecuencia de fisuras faciales con atributos sociogenéticos y del medioambiente en Chile. Anales de la Academia de Artes y Lenguas, 9: 16-24.

PESCE, H.

1951 Lepra en el Perú Precolombino. Conferencia de Ciencias Antropológicas, I. Actas y trabajos. Homenaje al IV Centenario de la Fundación de la UNMSM, Lima: 171-187.

PESSOA, S.B.; BARRETTO, M.P.

1948 Leishmaniose Tegumentar Americana. Rio de Janeiro: Ministério de Educação e Saúde: Serviço de Documentação.

POWELL, M.L.; COOK, D.C.

2005 The Myth of Syphilis. The natural history of treponematosis in North America. Gainesville: University of Florida.

PRAT, J.G.; MENDONÇA DE SOUZA, S.M.F.

2003 Prehistoric Tuberculosis in America: Adding comments to a literature review.
Memórias do Instituto Oswaldo Cruz, 98

(Suppl. I). Rio de Janeiro: 151-159.

RAMIREZ-HORTON, S.

1982 Retainers of the lords or merchants: a case of mistaken identify? In: El Hombre y su ambiente en los Andes. Osaka, Japón, National Museum of Ethnology (Senri Ethnological Studies, 10): 45-65.

RAVINES, R.

1985 Inventario de monumentos arqueológicos del Perú: Lima metropolitana. Lima: Municipalidad de Lima; Instituto Nacional de Cultura.

ROCA, E.

1953 Traumatismos encéfalo-craneanos.

Complicaciones, secuelas y tratamiento.

Lima: Imprensa Santa Maria.

ROSTWOROWSKI, M.D.C.

1978 Los Señorios de Lima y Canta. Lima: Instituto de Estudios Peruanos.

1986 La mujer en la época prehispánica. Serie Historia No 2, junio. Lima: Instituto de Estudios Peruanos.

1987 Conflicts over coca fields in 16th century Peru. In: Marcus, J. (Ed.) Memoirs of the Museum of Anthropology. Ann Arbor, University of Michigan. (Studies in Latin American Ethnohistory and Archaeology, 4).

1992 Historia del Tawantinsuyu. Lima: Instituto de Estudios Peruanos.

ROTHSCHILD, B.M.; HERSHKOVITZ, I.; DUTUOR, O.

1998 Clues Potentially Distinguishing Lytic Lesions of Multiple Myeloma from those of Metastatic Carcinoma. American Journal of Physical Anthropology, 105: 241-250.

ROWE, J.H.

1946 Inca culture at the time of the Spanish conquest. In: Steward, J.H. (Ed.) Handbook of South American Indians, vol. 2. Washington, DC, Smithsonian Institution: 183-330.

SAMPSON, P.D.

1997 Incidence of fetal alcohol syndrome and prevalence of alcohol-related neurodevelopmental disorder. Teratology, 56: 317-26.

SHADY, R.

1982 La cultura Nieveria y la interacción social en el mundo andino en la época Huari. Arqueológicas, 19. Lima, Museo Nacional de Antropologia y Arqueologia: 5-108.

TELLO, J.C.

1909 La antigüedad de la sifilis en el Perú. Tesis de bachiller en Medicina. UNMSM, Lima.

1967 Páginas escogidas. Selección y prólogo de Toribio Mejia Xesspe. Lima: UNSMSM. 
UBELAKER, D.H.

1989 Human Skeletal Remains. Excavation, Analysis and Interpretation. Manual on Archaeology, 2. 2a ed. Washington D.C.: Smithsonian Institution; Editorial Taraxacum.

1992 Human Skeletal Remains. Excavation, Analysis and Interpretation. Manual on Archaeology 2. Smithsonian Institution. Taraxacum, 2" printed. Washington D.C. VALDIVIA VERA, L.

1988 Odontoantropología peruana. Anomalias dentárias y paleopatología dento maxilar em cráneos de antiguos peruanos. Lima: Ministério da Presidência; Concytec.

VERANO, J.W.

1992 Referencias bibliográficas Prehistoric disease and demography in the Andes. In: J.W. Verano, J.W.; Ubelaker, D.H. (Eds.) Disease and Demography in the Americas. Washington D.C., Editora Uaxactum: 15-24.

VERANO, J.W.; LOMBARDI, G.

1999 Paleopatologia en Sudamérica Andina. Bulletin du Institut français d'Études Andines, 28 (1): 91-121.

VILLAR CÓRDOVA, P.E.

1984 Arqueología del Departamento de Lima. Lima: Ediciones Atusparia [1935].
1960 Los cráneos con deformación artificial "circular oblicua" de la provincia de Canta. Lima. In: Mejia Baca, J. (Ed.) Antiguo Perú, espacio y tiempo. Lima, Editora Mejia Baca: 351-363.

WEISS, P.

1984 Paleopatologia peruana. Boletín de Lima, 33: 17-52.

1958 Osteología cultural: practicas cefálicas. Primera parte: cabezas trofeo, trepanaciones y cauterizaciones. Lima: Universidad Nacional Mayor de San Marcos.

WILLIAMS, C.L.

1971 Centros ceremoniales tempranos en el valle del Chillón, Rimac y Lurin. Apuntes Arqueológicos, Lima, 1:1-4.

WILLIAMS, H.U.

1932 The Origin and Antiquity of Syphilis: the Evidence from Diseased Bones. Archives of Pathology, 13: 779-814; 931-983.

WINTER R.M.

1997 Mapping Syndromes to Genes. In: Thorogood, P. (Ed) Embryos, Genes and Birth Defects. Chickester, England: John Wiley and sons: 33-46.

ZIMMERMAN, M.R.; KELLEY, M.A.

1982 Atlas of Human Paleopathology. New York: Praeger Publishers CBS Educational and Professional Publishing a Division of CBS Inc. 